\title{
UM NOVO GÊNERO E ESPÉCIE DE BAETIDAE (EPHEMEROPTERA) DO ESTADO DE MINAS GERAIS, SUDESTE DO BRASIL
}

\author{
Frederico F. Salles ${ }^{1}$ \\ Carlos R. Lugo-Ortiz ${ }^{1}$
}

\begin{abstract}
A NEW GENUS AND SPECIES OF BAETIDAE (EPHEMEROPTERA) FROM THE STATE OF MINAS GERAIS, SOUTHEASTERN BRAZIL. Iguaira gen. nov., type species, I. poranga, sp. nov., based on one nymph from the State of Minas Gerais, Brazil, are proposed. The new taxon is distinguished by the labrum with multiple, unorganized setae dorsally; hypopharynx with three-lobed lingua; cleft mandibular incisors; labium with internally curved paraglossae; labial palps with second segment with strong, apically rounded distomedial process and third segment with truncate medial and apical margins; elongate tarsal claws with minute denticles; and absence of scales and scale bases.
\end{abstract}

KEYWORDS. Ephemeroptera, nymph, Iguaira, new genus, Brazil.

\section{INTRODUÇÃO}

O conhecimento faunístico da família Baetidae está muito aquém do satisfatório assim como para a grande maioria dos Ephemeroptera no Brasil. Embora significativos avanços taxonômicos tenham sido feitos recentemente (MCCAFFERTY \& LUGO-ORTIZ, 1995; Lugo-Ortiz \& McCAfFerty, 1995; 1996a, b, c; 1997; 1998; 1999a; SAlles \& Lugo-Ortiz, 2002a, b), a enorme área do Brasil, somada à sua quantidade e heterogeneidade de ambientes aquáticos sugerem que o número de espécies atualmente conhecido no país seja consideravelmente inferior ao real. Tal situação não só dificulta esforços para conservação e manejo de ambientes aquáticos, como também impede o esclarecimento da filogenia e biogeografia de Baetidae no Hemisfério Sul (L.-OrTiz \& MCCAFFERTY, 1999b).

Dos 26 gêneros de Baetidae registrados para a América do Sul (L.-OrTiz \& MCCAFFERTY, 1999b), 17 estão reportados para o Brasil, totalizando 37 espécies. As regiões Norte e Sul do Brasil apresentam grande parcela dos registros da família e as demais regiões representam lacunas. Na Região Sudeste, para o Espírito Santo não havia nenhum registro da família até recentemente (LUGO-OrTIz et al., 2002) e Minas Gerais tem apenas quatro espécies reportadas até o momento. Na Região Centro-Oeste, somente

1. Museu de Entomologia, Departamento de Biologia Animal, Universidade Federal de Viçosa, 36571-000, Viçosa, Minas Gerais, Brasil. (ffsalles@insecta.ufv.br; crlo122@hotmail.com) 
cinco espécies foram registradas (duas para o Estado do Mato Grosso, duas para Mato Grosso do Sul e uma para o Goiás). Até a Região Norte, com um número de gêneros registrado superior a muitos países neotropicais, quatro de seus sete estados (Amapá, Rondônia, Roraima e Tocantins) também permanecem sem registros da família.

Com base em uma ninfa, apresenta-se a proposição de um novo gênero e uma nova espécie procedente do Estado de Minas Gerais.

\section{Iguaira gen. nov.}

Ninfa madura. Cabeça mais longa que larga; quilha frontal ausente. Labro (fig. 1) mais largo que longo; margem anterior recurvada, medianamente escavada e provida de dentículo com ápice truncado; margem dorsal recoberta por numerosas cerdas longas, finas e simples, distribuídas aleatoriamente. Hipofaringe (fig. 2) com língua trilobada. Mandíbula esquerda (fig. 3) relativamente robusta; metade basal dos incisivos fusionada; prosteca robusta, apicalmente denteada; margem anterior (região entre incisivos e molar) desprovida de cerdas ou dentículos. Mandíbula direita (fig. 4) relativamente robusta; incisivos destacados basalmente; prosteca piliforme, apicalmente bifurcada; margem anterior desprovida de cerdas ou dentículos. Maxila (fig. 5) longa e estreita; palpo maxilar longo. Lábio (fig. 6) com glossa robusta, anteriormente arredondada; superfície ventral da glossa com numerosas cerdas longas, simples e finas; paraglossa recurvada internamente, com ápice estreito; palpo labial triarticulado, primeiro artículo disposto perpendicularmente em relação ao eixo longitudinal do lábio, segundo fortemente projetado disto-medianamente e com ápice arredondado e terceiro com margens mediana e apical truncadas e parcialmente fusionado ao segundo; pós-mento estreitado basalmente. Pernas (fig. 7) relativamente longas e estreitas; tíbia e tarso, em conjunto, mais longos que o fêmur; garras longas, com minúsculos dentículos. Tergitos (fig. 9) com espinhos na margem posterior, sem escamas ou bases de escamas. Esternitos (fig. 10) com espinhos na margem posterior e cerdas longas, finas e simples, esparsamente distribuídas; escamas ou bases de escamas ausentes. Brânquias (fig. 11) nos segmentos 1-7, ovaladas, estreitas, mais largas na região mediana, dispostas dorsoventralmente, margeadas por cristas bem espaçadas de onde partem cerdas minúsculas, simples e finas. Paraprocto (fig. 12) com espinhos marginais, destituído de escamas ou bases de escamas.

Etimologia. Nome atribuído pela combinação arbitrária das palavras do tronco lingüístico Tupi-guarani, Ig (água) e ayira (filha).

Espécie-tipo. Iguaira poranga sp. nov.

Distribuição. Brasil, Minas Gerais.

Comentários. Ninfas de Iguaira podem ser diferenciadas das dos demais Baetidae pela margem dorsal do labro (fig. 1) recoberta por inúmeras cerdas longas, finas e simples, distribuídas aleatoriamente; língua da hipofaringe (fig. 2) trilobada; mandíbulas (figs. 3, 4) robustas, com incisivos destacados; lábio (fig. 6) com paraglossa recurvada internamente; palpo labial (fig. 6) com segundo artículo fortemente projetado distomedianamente, apicalmente arredondado e o terceiro com margens mediana e apical truncadas; garras longas, com minúsculos dentículos; corpo sem escamas ou base de 
escamas.

Assim como as espécies dos gêneros Apobaetis Day, 1955, Callibaetis Eaton, 1881, Paracloeodes Day, 1955, Rivudiva Lugo-Ortiz \& McCafferty, 1998 e Waltzoyphius McCafferty \& Lugo-Ortiz, 1995, Iguaira também apresenta as mandíbulas com os incisivos destacados (fig. 4), a paraglossa recurvada internamente (fig. 6), corpo sem escamas ou base de escamas e pernas relativamente estreitas, com tíbia e/ou garras alongadas. Iguaira, Paracloeodes e Rivudiva possuem os incisivos da mandíbula direita basalmente fusionados, em contraste aos da esquerda, que são basalmente destacados. O labro e a hipofaringe são semelhantes aos de algumas espécies de Callibaetis. A morfologia do palpo labial, não só pela forma da projeção disto-mediana do segundo artículo, mas também pela forma truncada da margem mediana do terceiro artículo e abundantes cerdas finas e simples na margem externa do segundo e terceiro artículo, se assemelha a de Apobaetis e Waltzoyphius. Iguaira, Apobaetis e Waltzoyphius têm palpos maxilares longos e possuem a superfície ventral da glossa recoberta por cerdas diminutas, finas e simples.

\section{Iguaira poranga sp. nov.}

(Figs. 1-12)

Ninfa madura. Comprimento do corpo 6,4 mm. Comprimento dos filamentos caudais desconhecido. Coloração geral creme a castanha, com manchas castanho-escuras. Cabeça: padrão de coloração castanho, com região entre a base das antenas creme e área entre olhos compostos castanho-escura, com estrias transversais creme. Comprimento da antena desconhecido. Labro (fig. 1) 1,5 vezes mais largo que longo, com fileira de cerdas pectinadas na região ântero-mediana. Hipofaringe (fig. 2). Mandíbulas esquerda e direita cada uma com três dentículos nos incisivos externos e dois nos internos (figs. 3, 4); prosteca da mandíbula direita com ramos pectinados, sendo o ramo inferior mais longo que o superior (fig. 4). Maxila (fig. 5) com região mediana provida de duas cerdas isoladas, de comprimento médio, robustas e apicalmente afiladas; palpo maxilar tri-articulado, ultrapassando o ápice da gálea-lacínia; primeiro artículo curto, 0,15 vezes o comprimento do segundo; segundo artículo longo, distalmente aproximado do ápice da gálea-lacínia; terceiro artículo 1,25 vezes mais longo que o segundo, apicalmente arredondado e provido de cerdas diminutas, finas e simples. Lábio (fig. 6) com margem mediana da glossa recoberta por fileira de pequenas cerdas robustas, apicalmente afiladas e contínuas dorsalmente em direção à margem anterior; margem externa e ápice da superfície dorsal da glossa com cerdas simples, de comprimento médio; paraglossa ligeiramente maior que a glossa e com margem externa provida de fileira de cerdas longas e simples e margem mediana com poucas cerdas deste tipo; superfície dorsal da paraglossa com cerdas simples, médias a longas formando uma fileira próxima à margem mediana e esparsamente distribuídas próximas à margem externa; primeiro artículo do palpo labial 2,4 vezes mais longo que largo; segundo artículo com projeção disto-mediana densamente recoberta por cerdas longas, finas e simples e com ápice recoberto por cerdas pequenas, robustas e apicalmente afiladas; segundo terço apical da margem externa do segundo artículo, margem externa do terceiro artículo e superfície ventral do terceiro artículo densamente recobertas por cerdas longas, finas e simples; margem mediana do terceiro artículo provida de fileira de cerdas médias, relativamente robustas e apicalmente afiladas. Tórax: coloração 

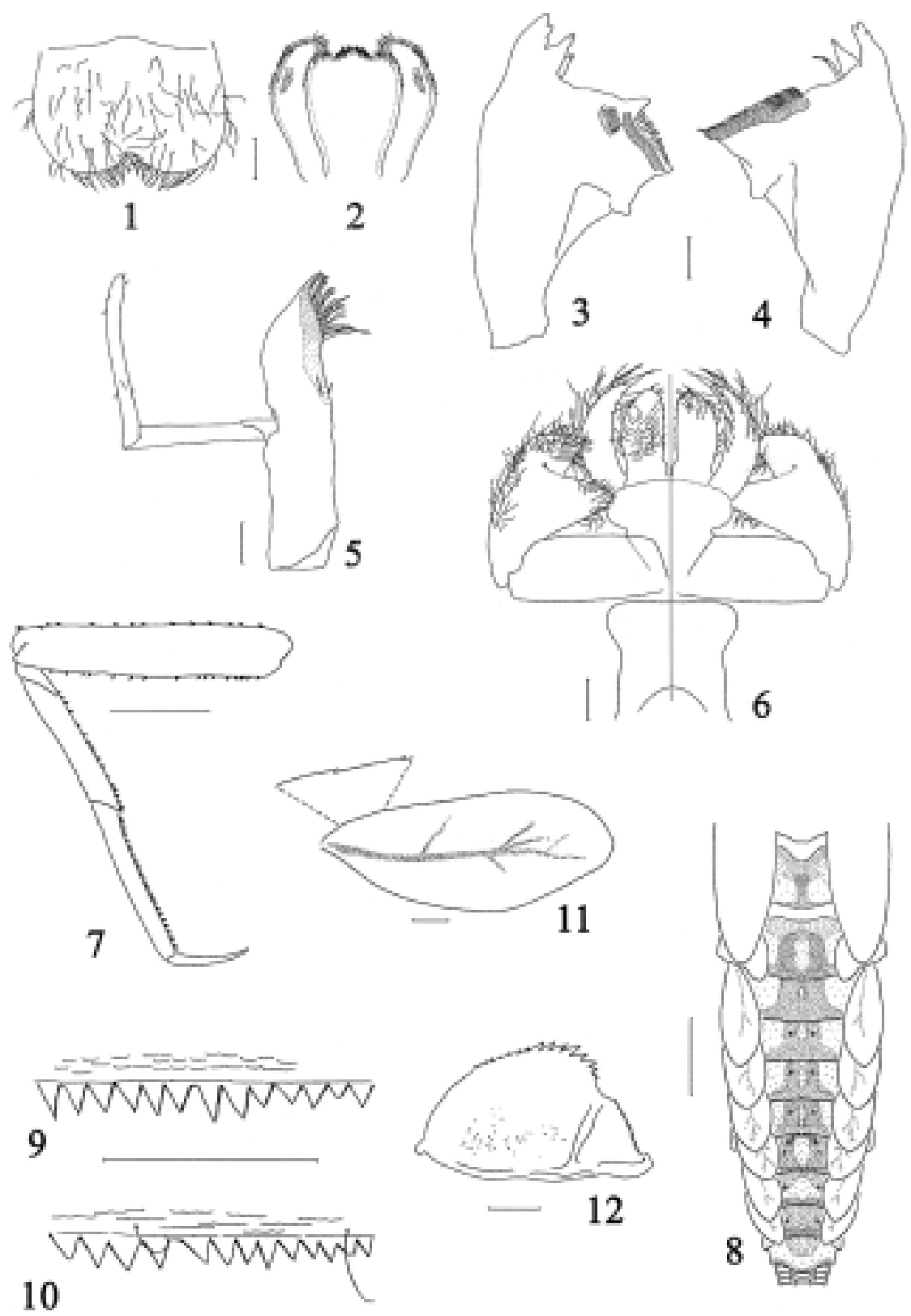

Figs. 1-12. Iguaira poranga sp. nov., ninfa: 1, labro, dorsal; 2, hipofaringe; 3, mandíbula esquerda; 4, mandíbula direita; 5, maxila direita; 6, lábio, esquerda-ventral; direita-dorsal; 7, perna anterior; 8 , padrão de coloração abdominal; 9 , margem posterior do tergito $4 ; 10$, margem posterior do esternito 4; 11, brânquia 4; 12, paraprocto. Escalas: $0,01 \mathrm{~mm}$, figs. $1-6,9-12 ; 0,5 \mathrm{~cm}$, figs. 7,8 . 
geral castanha a castanho-escura, sem padrão definido, exceto por duas pequenas manchas circulares castanho-escuras situadas póstero-medianamente no mesonoto. Teca alar posterior presente. Perna anterior (fig. 7) creme, com margens externas castanhoescuras; margens dorsal e ventral do fêmur providas de cerdas médias, simples e robustas, de ápice afilado; margens ventrais da tíbia e do tarso com diversas cerdas médias, robustas, simples e de ápice afilado, mais abundantes no tarso; margem dorsal da tíbia e tarso desprovida de cerdas; garras com 0,5 vezes o comprimento do respectivo tarso. Abdome (fig. 8): padrão de coloração abdominal castanho-claro, com manchas castanhas, em geral mais largas na margem posterior e estreitando-se anteriormente, e com pequenas manchas circulares castanho-escuras nos tergitos 4 a 9. Espinhos da margem posterior dos tergitos (fig. 9) e esternitos (fig. 10) de formato regular; zonas de fricção anterolaterais presentes nos esternitos. Brânquias (fig. 11) com ramo principal da traquéia bem definido, exceto pelo primeiro par. Paraprocto (fig. 12) com 17 espinhos, aumentando de comprimento apicalmente, exceto pelos quatro últimos.

Material-tipo. BRASIL, Minas Gerais: Itamonte, Rio Aiuruoca (pedra), holótipo ninfa $\underset{\text { C, }}{ }$ 08.IX.2000, N. Ferreira Jr. col. Depositado na coleção do Departamento de Zoologia, Instituto de Biologia, Universidade Federal do Rio Janeiro, Rio de Janeiro, Brasil (DZRJ).

Etimologia. Derivado do tronco lingüístico Tupi-guarani, poranga, belo.

Comentários. I. poranga diferencia-se pelo palpo maxilar (fig. 5) triarticulado e comprimento relativo entre os artículos, pela disposição e abundância de cerdas no lábio (fig. 6), principalmente na margem externa do segundo e terceiro artículos, pelo comprimento relativo das garras (metade do comprimento do respectivo tarso) (fig.7) e pelo número de espinhos no paraprocto (fig. 12). Como apenas um indivíduo foi examinado, o padrão de coloração abdominal (fig. 8) pode ser susceptível à variação como em algumas espécies de Baetidae.

Agradecimentos. À Fundação de Coordenação de Aperfeiçoamento de Pessoal de Nível Superior (CAPES) por prover fundos; ao Dr J. E. Serrão (UFV) por comentários e críticas ao manuscrito.

\section{REFERÊNCIAS BIBLIOGRÁFICAS}

Lugo-Ortiz, C. R. \& McCafferty, W. P. 1995. Three distinctive new genera of Baetidae (Insecta, Ephemeroptera) from South America. Ann. Limnol., Paris, 31:233-243.

_. 1996a. Aturbina georgei gen. et esp. n.: a small minnow mayfly (Ephemeroptera: Baetidae) without turbinate eyes. Aq. Insects, Lisse, 18:175-183.

1996b. The genus Paracloeodes (Insecta: Ephemeroptera: Baetidae) and its presence in South America. Ann. Limnol., Paris, 32:161-169.

. 1996c. Taxonomy of the neotropical genus Americabaetis, new status (Insecta: Ephemeroptera:

Baetidae). Stud. neotrop. Fauna Environ., Lisse, 31:156-169.

1997. First report and new species of the genus Apobaetis (Ephemeroptera: Baetidae) from South America. Aq. Insects, Lisse, 19:243-246.

1998. Five new genera of Baetidae (Insecta: Ephemeroptera) from South America. Ann.

Limnol., Paris, 34:57-73.

1999a. Revision of the South American species of Baetidae (Ephemeroptera) previously placed

in Baetis Leach and Pseudocloeon Klapálek. Ann. Limnol., Paris, 35:257-262.

_. 1999b. Global biodiversity of the mayfly family Baetidae (Ephemeroptera): a generic perspective. Trends Ent., New Delhi, 2:45-54.

Lugo-Ortiz, C. R.; Salles, F. F. \& Furieri, K. S. 2002. First records of small minnow mayflies 
(Ephemeroptera; Baetidae) from the State of Espírito Santo, southeastern Brazil. Lundiana, Belo Horizonte, 3:79-80.

McCafferty, W. P. \& Lugo-Ortiz, C. R. 1995. Cloeodes hydation, n. sp. (Ephemeroptera: Baetidae): an extraordinary, drought tolerant mayfly from Brazil. Ent. News, New Jersey, 106:29-35.

Salles, F. F. \& Lugo-Ortiz, C. R. 2002a. A distinctive new species of Apobaetis (Ephemeroptera: Baetidae) from Mato Grosso and Minas Gerais, Brazil. Zootaxa, Auckland, 35:1-6.

2002b. Primeiro registro do gênero Harpagobaetis Mol (Ephemeroptera: Baetidae) para o Brasil. Lundiana, Belo Horizonte, 3:155.

Recebido em 30.04.2002; aceito em 17.02.2003.

Iheringia, Sér. Zool., Porto Alegre, 93(2):201-206, 30 de junho de 2003 